\title{
A study of centrifugal pressing of curd for paneer production
}

\author{
AK Agrawal $^{{ }^{*}}$, Sapna Jain ${ }^{1}, K_{K}$ Sandey $^{1}, C_{\text {Sahu }}{ }^{1}$ and S Kartikyen ${ }^{2}$
}

Received: 27 March 2021 / Accepted: 08 August 2021 / Published online: 31 October 2021

(c) Indian Dairy Association (India) 2021

\begin{abstract}
Paneer is one of the popular heat-acid coagulated indigenous milk product in Indian cuisine. Traditionally, it is prepared by removing whey from acidified milk by pressing method. The present investigation was performed to study the effect of independent parameters like initial thickness of curd $(1.5,3.0$ and $4.5 \mathrm{~cm})$, speed of rotation of centrifuge $(500,1000$ and $1500 \mathrm{rpm})$ and time of rotation $(5,10 \mathrm{and} 15 \mathrm{~min}$.) on centrifugal pressing of curd for paneer making. The effect of initial thickness, speed of rotation and pressing time of curd on moisture, solid loss and hardness ratio of centrifugal pressing were determined. A dimensionless number called as 'centrifugal pressing number' was formed to assess the changes occurred during pressing. It was found that pressing time had the maximum effect on solid loss and hardness ratios but the rotational speed had maximum effect on moisture ratio. The thickness of curd had the least effect on moisture and solid loss ratio of pressing.
\end{abstract}

Keywords: Centrifuge, Hardness ratio, Moisture ratio, Paneer, Solid loss ratio

${ }^{1}$ Dairy Engineering Department, College of Dairy Science \& Food Technology, Dau Shri Vashudev Chandrakar Kamdhenu Vishwavidhyala, Durg, C.G.

${ }^{2}$ Dairy Technology Department, College of Dairy Science \& Food Technology, Dau Shri Vashudev Chandrakar Kamdhenu Vishwavidhyala, Durg, C.G.

AK Agrawal $(\square)$

Dairy Engineering Department, College of Dairy Science \& Food Technology, Dau Shri Vashudev Chandrakar Kamdhenu Vishwavidhyala, Durg, C.G.

Email id.: akagrawal.raipur@gmail.com
Paneer is obtained by acid coagulation of heated milk with citric acid and contains nearly all milk proteins, fat, insoluble salts and colloidal matter. It is similar to an unripened variety of soft cheese which is extensively used in the preparation of a variety of culinary dishes and snacks (Kumar et al. 2014). Paneer is usually white in appearance with sweetish acidic nutty flavor, close knit texture and spongy body (Bandyopadhyay and Mathur 1987). Due to increasing demand of cost-effective high quality product, there is need for upgrading and scaling-up of technology especially for continuous production of paneer with higher product yield. Aheer (1986) used bowl of basket centrifuge with perforations on its periphery for removal of whey from coagulated mass. Agrawal and Das (2001) studied the phenomena of pressing of curd by analysing the delayed method of pressing of curd, which is being practiced in traditional method of paneer manufacturing. Mudgal and Agrawala (2010) measured the textural characteristics and overall sensory of paneer made from buffalo milk. Halder et al. (2011) developed kinematic half-turn nut paneer pressing mechanism for medium scale application. Considering the limited amount of studies carried out, the present study was undertaken to study the effect of centrifugal pressing of curd for production of paneer.

The buffalo milk ( $7 \pm 0.3 \%$ fat; $16 \pm 0.5 \% \mathrm{TS})$ was procured from local market. Milk was first heated to $95^{\circ} \mathrm{C}$ and then cooled to $70^{\circ} \mathrm{C}$. It was then coagulated by mixing $22.7 \mathrm{~g} / \mathrm{l}$ citric acid solution previously heated to $70^{\circ} \mathrm{C}$ in the ratio of $1: 5$ (acid:milk). Residence time of 1 min was allowed before straining of whey by muslin cloth. The pressing of curd was carried out using Sorvall centrifuge swinging bucket rotor (make: Thermo Fisher Scientific). The operating parameters were initial thicknesses of curd (1.5, 3.0 and $4.5 \mathrm{~cm})$, speed of rotation of centrifuge $(500,1000$ and $1500 \mathrm{rpm}$ ) and time of rotation (10,20 and $30 \mathrm{~min})$. The pressed curd samples were rotated with chilled water for $15 \mathrm{~min}$ in same centrifuge. The control sample was prepared by traditional method (Agrawal and Das 2001). The centrifugal pressing method was evaluated by quantity of whey removed i.e. moisture ratio of pressing, $\mathrm{M}_{\mathrm{rp}}$, (ratio of moisture content of pressed curd to the moisture content of curd before pressing), Solid loss ratio of pressing, $\mathrm{S}_{\mathrm{rp}}$ (ratio of weight of solid lost with whey to the initial dry weight of curd) and Hardness ratio of pressing, $\mathrm{H}_{\mathrm{rp}}$ (ratio of hardness of pressed curd to the hardness of curd before pressing) 
Table 1 ANOVA for the effect of independent variable on various pressing ratios

\begin{tabular}{lllllll}
\hline Source of variation & \multicolumn{7}{l}{$\begin{array}{l}\text { Pressing ratios } \\
\text { Moisture }\end{array}$} & \multicolumn{3}{l}{$\begin{array}{l}\text { Solid loss } \\
\end{array}$} & $\begin{array}{l}\text { Mean sum } \\
\text { of squares }\end{array}$ & F-value & $\begin{array}{l}\text { Mean sum } \\
\text { of squares }\end{array}$ & F-value & $\begin{array}{l}\text { Mean Hardness } \\
\text { sum of squares }\end{array}$ & F-value \\
\hline Thickness & 00.400 & $17.51^{* *}$ & 0.000093 & $62.427^{* *}$ & 0.726 & $30.856^{* *}$ \\
Speed of rotation & 0.02318 & $104.04^{* *}$ & 0.000168 & $112.339^{* *}$ & 0.705 & $29.958^{* *}$ \\
Time & 0.01900 & $84.45^{* *}$ & 0.000338 & $225.940^{* *}$ & 1.333 & $56.667^{* *}$ \\
Error & 0.00020 & & 0.000001 & & 0.024 & ${ }^{*}$
\end{tabular}

F-value $(1,23)$ at $1 \%=7.88^{* * *}$ Significant at $1 \%$

were taken as the dependent variables. These parameters were considered as the measures for evaluating the pressing process. The recovery of milk solids in curd, $\mathrm{R}_{\mathrm{c}}(\mathrm{kg}$ milk solids in curd $/ \mathrm{kg}$ solids in milk) and yield of paneer, $\mathrm{Z}_{\mathrm{c}}(\mathrm{kg}$ paneer $/ \mathrm{kg}$ milk) (Agrawal and Das 2001) were also calculated. For analyzing the centrifugal pressing a dimensionless number called 'Centrifugal Pressing Number' $\mathrm{N}_{\mathrm{cp}}$ was conceptualized which has combination of all independent input variables.

$$
N_{c p}=\frac{\left[2 \pi^{2} n^{2}\left(r_{2}^{2}-r_{1}^{2}\right) \theta_{p}^{2}\right]}{B^{2}}
$$

Where, $\mathrm{n}=$ Speed of rotation of centrifuge, rps; $r_{1}=$ Distance of whey drainage surface of the curd from axis of rotation (outer), $\mathrm{m} ; \mathrm{r}_{2}=$ Distance of free surface of the curd from axis of rotation (inner), $\mathrm{m}$; $\hat{\mathrm{o}}_{\mathrm{p}}=$ Time of run of centrifuge for pressing of curd, $\mathrm{s}$ and $\mathrm{B}=$ Initial thickness of curd, $\mathrm{m}$. The moisture, solid loss and hardness ratios were converted into coded values to bring the variation of all ratios in a single range of non-dimensional code values to compare their behavior against Centrifugal pressing number. Therefore, the ratios of moisture, solid loss and hardness were brought to uniform range of -1 to +1 by converting their variation in terms of coded values, $\mathrm{N}_{\mathrm{c}}$, using the following equations:

$$
N_{c}=\frac{\left(X-x_{\text {mean }}\right)}{\left(X_{\text {mean }}-x_{\text {min }}\right)}
$$

Where, $\mathrm{x}=$ Observed value of variable; $\mathrm{x}_{\text {mean }}=$ Mean value of variable; $x_{\min }=$ Minimum value of variable. Paneer is known for its excellent chewing properties. Higher values of hardness will lead to higher chewiness (Mudgal and Agrawala 2010). Therefore, during pressing curd should attain high value of moisture and hardness ratios alongwith low value of solid loss ratio. The moisture content of milk, whey, curd, pressed curd and paneer were determined by drying at $102 \pm 2^{\circ} \mathrm{C}$ (IS: 5162, 1980) and fat (IS: 1224, 1977). Hardness of curd, pressed curd and paneer were determined using Steven's Texture Analyzer. A $3^{3}$ factorial experimental design was adopted to evaluate the combined effect of selected independent variables (Snedecor and Cocharan, 1967). The expulsion of whey due to

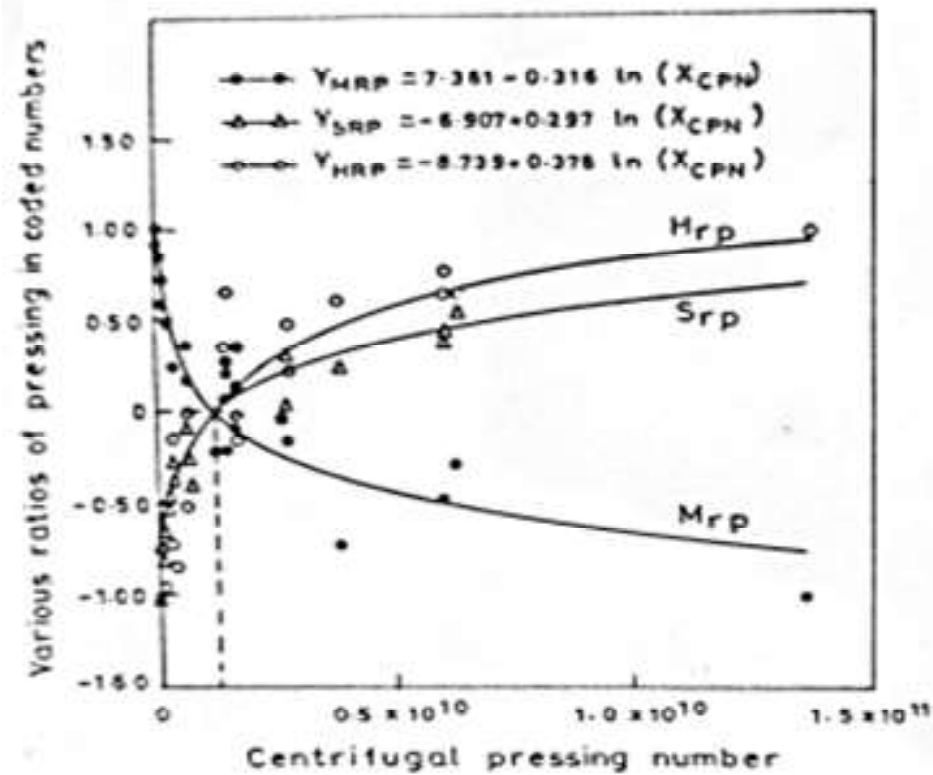

Fig. 1 Effect of centrifugal pressing number during centrifugal pressing of curd on various pressing ratios

centrifugation caused average reduction of 0.015 (in fraction) in recovery of milk solids from original value of recovery of milk solids 0.701 curd (in fraction) which was obtained after straining of whey from coagulated mass.

The ANOVA for the effect of process variables on moisture, solid loss and hardness ratios of pressing is shown in Table 1. The effect of all the pressing variables on the moisture ratio, solid loss ratio and hardness ratio were highly significant $(p<0.01)$. The initial thickness had the least significant effect on moisture and solid loss ratio. The selected levels of pressing time had highest effect on the solid loss and hardness ratio. The speed of rotation of centrifugal machine had the most significant, significant and least significant effects on moisture, solid loss and hardness ratios, respectively. It came to notice that the high speed of rotation caused more moisture removal and solid loss without much gain in hardness of pressed curd. 
The variation of coded values of these ratios with respect to centrifugal pressing number is shown in Fig. 1. It showed that with the increase in centrifugal pressing number, the moisture ratio decreases. This might be due to centrifugation of curd at high speed with longer time leads to more removal of moisture from curd. The solid loss ratio increased with the increase in centrifugal pressing number. This might be due to longer time of centrifugal pressing of curd at high speed. The hardness ratio also increased with the increase in centrifugal pressing number of centrifugal pressing of curd. The rate of decrease in moisture ratio and increase in solid loss and hardness ratios decreased with the increase in centrifugal pressing number.

The desired combination of pressing ratios was obtained from point of intersection. The intersection of all three pressing ratios at centrifugal number of $1.25 * 10^{10}$ was found to be equal to 0.000 (in terms of coded value). The desired pressing ratios in coded values $(0.000)$ were converted back to original values which were the mean values of moisture $(0.808)$, solid loss $(0.029)$ and hardness (1.731) ratios. In the present set of experimentation, the recovery of solids in paneer varied from 0.563 to $0.624 \mathrm{~kg}$ solids/ $\mathrm{kg}$ solids in milk and yield of paneer varied from 0.193 to $0.233 \mathrm{~kg}$ paneer $/ \mathrm{kg}$ milk. Similar result was also reported by Bhattacharya et al. (1971) that was $0.209 \mathrm{~kg} / \mathrm{kg}$ of milk.

\section{Conclusion}

In this study the centrifugal pressing number was developed to optimize the independent variables (initial thickness of curd, speed of rotation and time of rotation of centrifuge) to ensure minimum solid loss and desired hardness of centrifuged pressed paneer. If the levels of independent variables are known, the different pressing ratios can be estimated with the help of Centrifugal pressing number. The developed empirical mathematical relationship is a useful tool for predicting the behavior of curd pressing phenomena, when different combination of parameters is adopted in centrifugal pressing.

\section{References}

Agrawal AK, Das H (2001) Production of Paneer: Analysis of delayed pressing of curd. Egyptian J Dairy Sci 29: 63-76

Aheer HL (1986) Development and evaluation of a process for continuous production of chhana and paneer. M.Tech Thesis, Indian Institute of Technology, Kharagpur, India

Bandyopadhyay AK, Mathur BN (1987) Indian milk products: A compendium. Dairy India.

Bhattacharya DC, Mathur ON, Srinivasan MR, Samlik O (1971) Studies on the methods of production and shelf life of paneer (cooking type of acid coagulated cottage cheese). J Food Sci Technol 8: 117120

Halder K, Kumar B, Minz PS (2011) Design and development of kinematic half-turn nut paneer pressing mechanism for medium-scale application. Indian J Dairy Sci 64: 466-471

Indian Standards (IS: 1224, Part I) 1977, Determination of fat by Gerber method. Bureau of Indian Standards, New Delhi, India.

Indian Standards (IS: 5162) 1980, Specification for Chhana. Bureau of Indian Standards, New Delhi, India.

Kumar S, Rai DC, Niranjan K, Bhat Z (2014) Paneer - An Indian soft cheese variant: A review. J Food Sci Technol 51(5): 821-831. DOI: $10.1007 / \mathrm{s} 13197-011-0567-\mathrm{x}$

Mudgal VD, Agrawala SP (2010) Textural analysis of buffalo paneer. Indian J Dairy Sci 63(3): 81-85

Snedecor GW, Cochran WG (1967) Statistical Methods, 6th Edition. Oxford and IBHP publishing company, New Delhi, India 